\title{
Sexual Orientation and Sex Differences in Adult Chronic Conditions, Health Risk Factors, and Protective Health Practices, Oregon, 2005-2008
}

\author{
Rodney Y. Garland-Forshee, MS; Steven C. Fiala, MPH; Duyen L. Ngo, MPH, PhD; \\ Katarina Moseley, MPH
}

\begin{abstract}
Suggested citation for this article: Garland-Forshee RY, Fiala SC, Ngo DL, Moseley K. Sexual Orientation and Sex Differences in Adult Chronic Conditions, Health Risk Factors, and Protective Health Practices, Oregon, 2005-2008. Prev Chronic Dis 2014; 11:140126. DOI: http://dx.doi.org/10.5888/pcd11.140126.
\end{abstract}

\section{PEER REVIEWED}

\section{Abstract}

\section{Introduction}

Research on lesbian, gay, and bisexual (LGB) individuals' health and health practices has primarily consisted of convenience studies focused on HIV/AIDS, substance use, or mental illness. We examined health-related disparities among Oregon LGB men and women compared with heterosexual men and women using data from a population-based survey.

\section{Methods}

Data from the 2005 through 2008 Oregon Behavioral Risk Factor Surveillance System were used to examine associations between sexual orientation and chronic conditions, health limitations, health risk factors, and protective health practices.

\section{Results}

Compared with heterosexual women, lesbian and bisexual women were significantly more likely to smoke cigarettes, be obese, binge drink, and have chronic conditions, and less likely to engage in protective health practices. Compared with heterosexual men, gay men were significantly less likely to be obese, more likely to binge drink, and more likely to engage in protective health practices.
Compared with heterosexual men, bisexual men were significantly more likely to have a physical disability, smoke cigarettes, binge drink, and more likely to get an HIV test.

\section{Conclusions}

Health disparities among Oregon LGB individuals were most prominent among lesbian and bisexual women. Gay men had the most protective health practices, but they were more likely than heterosexual men to engage in risky behaviors that lead to chronic diseases later in life. Targeted public health interventions should be provided in environments that avoid stigmatizing and discriminating against LGB individuals where they live, work, learn, and socialize.

\section{Introduction}

Research on lesbian, gay, and bisexual (LGB) individuals' health and health practices has primarily consisted of convenience studies focused on HIV/AIDS, substance use, or mental illness $(1,2)$. Recently, population-based studies have assessed chronic conditions, health risk factors, disabilities, physical or mental health limitations, and health practices of the adult LGB population $(3,4)$. These and other studies reported that lesbian or bisexual women had higher odds of having arthritis $(5)$, asthma $(3,4)$, and diabetes (4), and were more likely to smoke cigarettes $(3,4)$, abuse alcohol (3), and be overweight compared with heterosexual women (4). Lesbian and bisexual women were also more likely than heterosexual women to report poor health (6) and were less likely to receive preventive screenings $(4,7)$. Compared with heterosexual men, gay or bisexual men had higher odds of having asthma (3), were more likely to smoke cigarettes $(3,4)$, and were more likely to abuse alcohol (8).

To understand the health of LGB adults in Oregon, the Oregon Public Health Division added a consistent sexual orientation ques- 
tion to the state's Behavioral Risk Factor Surveillance System (BRFSS) survey in 2005. Addition of sexual orientation questions to state and federal surveys is a key recommendation of the 2011 Institute of Medicine (IOM) report on the health of LGB and transgender people and is an objective of Healthy People 2020 $(2,9)$. The IOM acknowledges that there is incomplete information about the health of LGB people, a group that is becoming increasingly visible and more socially acknowledged (2). This study addresses gaps in the literature by assessing additional chronic disease risk factors and preventive health behaviors and by controlling for additional demographic factors that are known to shape LGB health outcomes.

\section{Methods}

Oregon BRFSS data from 2005 through 2008 were combined to provide a sufficient sample of LGB individuals for analysis. The BRFSS is a population-based telephone survey of Oregon adults conducted in collaboration with the Centers for Disease Control and Prevention (CDC). Data were collected from randomdigit-dialed landline telephones with 1 adult respondent randomly selected from each household. Eligible respondents were noninstitutionalized English- or Spanish-speaking adults. All data have sample weights based on selection probability of a respondent and were poststratified to the age and sex characteristics of the Oregon population. All measures used for analysis were based on questions developed by $\mathrm{CDC}$, except for the question on a respondent's sexual orientation; CDC did not have a sexual orientation question at the time of survey administration.

\section{Measures}

Sexual orientation. Starting in 2005, a consistent question on sexual orientation was added to the Oregon BRFSS. Survey respondents were asked, "Now I'm going to ask you a question about sexual orientation. Do you consider yourself to be a) heterosexual, that is, straight; b) homosexual, that is gay or lesbian; c) bisexual; or d) other?" For this study, the sexual orientation question was combined with the respondent's sex to create the classification groups of gay, bisexual, and heterosexual men and lesbian, bisexual, and heterosexual women. From 2005 through 2008, 44,560 adult Oregonians were asked their sexual orientation on the Oregon BRFSS. A small group ( $\mathrm{n}=1,814 ; 4.1 \%$ unweighted) did not provide their sexual orientation, restricting the sample to 42,746 adult Oregonians.

Demographics. All demographic variables were recoded for analysis. Respondent age (in years) was recoded into 3 groups: 18 to 34,35 to 54 , and 55 years or older. Relationship status was combined into married or a member of an unmarried couple, formerly married, or never married. Unmarried couples were grouped with married respondents because, in Oregon, LGB couples could not marry at the time of survey administration. Educational attainment was grouped into 3 categories: high school degree or GED (general educational development) or less, attended 1 to 3 years of college, or attended 4 or more years of college. Rural or urban residency was determined by using zip codes classified by RuralUrban Commuting Area (RUCA) codes (10). Urban areas had RUCA codes of $1.0,1.1,2.0,2.1,3.0,4.1,5.1,7.1,8.1$, or 10.1 ; rural areas had codes of 4.0, 4.2, 5.0, 5.2, 6.0, 6.1, 7.0, 7.2, 7.3, $7.4,8.0,8.2,8.3,8.4,9.0,9.1,9.2,10.0,10.2,10.3,10.4,10.5$, or 10.6 (10). Employment status was categorized as employed, unemployed or unable to work, or not in the workforce. Annual household income was categorized as less than $\$ 20,000, \$ 20,000$ to $\$ 49,999$, and $\$ 50,000$ or more. Because of the limited sample of nonwhite and Latino respondents, all nonwhite and Latino Oregonians were combined for comparison to white non-Latinos.

Chronic conditions and health limitations. Chronic conditions assessed included the following: asthma, arthritis, diabetes, high blood pressure, high cholesterol, and cardiovascular disease. Cardiovascular disease questions measured respondents who had ever had a heart attack, angina or coronary heart disease, or a stroke. Two questions on disabilities asked respondents if they used any special equipment and if they were limited in any activities. Respondents who reported activity limitations of 7 or more days during the last 30 days because of poor mental or physical health were assigned to the poor mental/physical health category.

Health risk factors. Current cigarette smokers were defined as having smoked 100 or more cigarettes in their lifetime and currently smoking cigarettes on some or all days. Obesity was established for respondents who had a body mass index (weight in kilograms divided by the square of height in meters) of $30 \mathrm{~kg} / \mathrm{m}^{2}$ or higher. $\mathrm{CDC}$ defines heavy drinking as consuming more than 1 drink per day on average in the last month for women and consuming more than 2 drinks per day on average in the last month for men. CDC defines binge drinking as consuming 4 or more drinks during 1 occasion in the last month for women and consuming 5 or more drinks during 1 occasion in the last month for men.

Protective health practices. Receiving a health checkup was defined as having had a routine checkup with a doctor in the past 2 years. Insurance status classified people into those with or without current health insurance. Influenza immunization included those who had received an influenza shot or spray, mist, or drop in the nose in the past year. Whether participants met recommendations for fruits and vegetables consumption and physical activity was

The opinions expressed by authors contributing to this journal do not necessarily reflect the opinions of the U.S. Department of Health and Human Services, the Public Health Service, the Centers for Disease Control and Prevention, or the authors' affiliated institutions. 
based on CDC recommendations appropriate for the period of this study (11). Other measures included respondents who had their teeth cleaned in the last 12 months, had ever been tested for HIV, and had their cholesterol checked in the past 5 years.

\section{Data analyses}

Analyses were conducted using the Stata statistical software (StataCorp LP; version 11), and we established significance at a .05 level. Pearson $\chi^{2}$ test for independence was used to determine whether demographic variables significantly differed by sexual orientation and sex. Demographic variables that were significant were assessed as independent variables for logistic regression models. Independent variables for the final logistic regression models were chosen using the backward elimination variable selection process. Age, education, relationship status, and urban or rural residency were included in the final models. Rural or urban residency was not a significant contributor in some of the final models; however, previous literature has established this variable as associated with health outcomes among LGB people $(12,13)$. Although employment status and household income were each significant for women in bivariate analyses, they were not included for multivariable adjustment because they did not significantly contribute to the final models.

\section{Results}

A total of 16,475 men and 26,271 women respondents were included in the analysis. Of these respondents, 268 men self-identified as gay and 123 as bisexual; 347 women self-identified as lesbian and 322 as bisexual.

\section{Demographics}

Among men, $1.6 \%$ reported being gay and $0.7 \%$ bisexual; among women, $1.3 \%$ reported being lesbian and $1.2 \%$ bisexual. Individuals who reported being gay, lesbian, or bisexual were younger than heterosexual men and women; bisexuals were youngest in each sex group (Table 1). Race and ethnicity were not associated with sexual orientation in either men or women. Relationship status, educational attainment, and living in an urban or rural area were significantly different by sexual orientation. More heterosexuals were married or members of an unmarried couple compared with gay men, lesbian women, and bisexual men and women. Among men, gay men were the most educated, and bisexual and heterosexual men had similar levels of educational attainment. Among women, lesbian women were the most educated, followed by bisexual, and then heterosexual women. Gay men, lesbian women, and bisexual men and women were more likely to live in urban areas compared with their heterosexual counterparts. Employment status and household income were significantly different by sexu- al orientation for women, but not for men. Lesbian women were more likely to be employed compared with bisexual and heterosexual women, and lesbian and heterosexual women had a higher household income than bisexual women.

\section{Chronic conditions and health limitations}

Gay and heterosexual men were not significantly different with respect to the chronic conditions and health limitations assessed in the study (Table 2). Bisexual men were significantly more likely to have a disability that limits activities compared with heterosexual men. Lesbian women were significantly more likely to have been diagnosed with arthritis and to have a disability that limits activities compared with heterosexual women. Compared with heterosexual women, bisexual women were significantly more likely to have poor mental or physical health, asthma, a disability that limits activities, and a disability that requires the use of special equipment.

\section{Health risk factors and protective health practices}

Compared with heterosexual men, gay men were significantly less likely to be obese and significantly more likely to binge drink (Table 3). Bisexual men were significantly more likely to be current cigarette smokers and to binge drink compared with heterosexual men. Lesbian and bisexual women were significantly more likely to be current cigarette smokers and to be obese compared with heterosexual women. Bisexual women were also significantly more likely to binge drink compared with heterosexual women, but lesbian women were not $(P=.054)$. However, because the significance level for binge drinking among lesbian women was borderline, we included them in the discussion as significant.

Compared with heterosexual men, gay men were significantly more likely to have received an influenza immunization and ever have been tested for HIV (Table 3). Bisexual men were significantly more likely to ever have been tested for HIV compared with heterosexual men. Compared with heterosexual women, lesbian women were significantly less likely to have had their teeth cleaned in the past 12 months. Bisexual women were significantly less likely to have health insurance, to have had a health checkup in the last 2 years, and to have had their teeth cleaned in the past 12 months and were more likely to ever have been tested for HIV compared with heterosexual women.

\section{Discussion}

This study confirms many LGB health disparities found in prior studies and expands upon the chronic conditions, health risk factors, and protective health practices previously investigated using BRFSS data. New to the literature are results related to arthrit-

The opinions expressed by authors contributing to this journal do not necessarily reflect the opinions of the U.S. Department of Health and Human Services, the Public Health Service, the Centers for Disease Control and Prevention, or the authors' affiliated institutions. 
is, obese weight status separate from overweight status, binge drinking, cholesterol screening, receiving a health checkup, HIV testing practices, and dental care. Although a previous study of LGB health controlled for age and education (4), our study additionally controls for the effects of relationship status and rural or urban residency. We found that the LGB population was less likely to be married or a member of an unmarried couple and more likely to live in an urban area. Marriage provides economic and health benefits $(14,15)$, and rural and urban residency confers different health disparities, particularly in the extremely rural or urban areas $(12,13)$. Cherlin hypothesizes that same-sex unmarried couples occupy a middle position, reporting better health than different-sex unmarried couples but poorer health than married couples (16).

Consistent with an analysis of health outcomes among LGB individuals in Washington State (4), this study shows that lesbian and bisexual women have more elevated health risks than heterosexual women. In contrast, gay or bisexual men are at elevated odds for only 3 of the health issues assessed, and gay men engage in more protective health practices compared with heterosexual men. It is not known why bisexual women have worse health outcomes than other groups. Dilley et al (4) hypothesize that bisexual orientation may contribute to negative health outcomes because of the stress associated with self-perceptions that shift between heterosexuality and homosexuality.

Lesbian women and bisexual men and women have a significantly higher prevalence of current cigarette smoking, lesbian and bisexual women have a significantly higher prevalence of obesity, and all LGB groups have a significantly higher prevalence of binge drinking. These behaviors and conditions are all leading preventable causes of premature death in the United States $(17,18)$. The decreased likelihood of being obese among gay and bisexual men could be a result of high body dissatisfaction (19). In contrast, a recent study suggested that lesbian and bisexual women have higher rates of body satisfaction and higher ideal weights compared with heterosexual women (20), which could explain higher rates of obesity. However, another study found no such difference (21). Our study indicates that cigarette smoking among gay men is higher than among heterosexual men, although not significantly higher. Other studies show significantly higher cigarette smoking prevalence in the gay community $(3,4)$. It is unknown why this study's results differed, and more research is warranted. We also found binge drinking to be significantly higher among all sexual orientation minority groups compared with heterosexual men and women. This finding confirms those of a Massachusetts study that reported higher binge drinking among bisexual women compared with heterosexual women; however, the Massachusetts study did not find the same disparity among gay and bisexual men or among lesbian women (3).

LGB individuals did not differ from their heterosexual counterparts with respect to most of the chronic conditions assessed. This is likely because LGB men and women in this study were younger than heterosexual men and women and therefore less likely to have chronic conditions often associated with older age. However, the LGB groups were more likely to report risk factors associated with developing chronic conditions later in life. Although gay men in this study were less likely to be obese and more likely to engage in protective health behaviors, they were also more likely to binge drink and, although not seen in this study, previous literature has consistently found that gay men were significantly more likely to smoke cigarettes compared with heterosexual men $(3,4)$. A recent study confirms that older LGB adults continue to be disproportionately affected by chronic disease risk factors, including cigarette smoking and excessive drinking (22), and are more likely to report chronic conditions associated with these risk factors, including cardiovascular disease among lesbian and bisexual women and poor physical health among gay and bisexual men (22).

Disparate engagement in unhealthy behaviors is also observed in other vulnerable populations, including those with low socioeconomic status $(23,24)$. However, gay men and lesbian women in this study have higher educational attainment and are more likely to be employed than heterosexual men and women. A possible explanation is minority stress. The excessive and chronic stress to which LGB individuals are exposed as a result of stigmatization may lead to unhealthy coping mechanisms regardless of their higher educational attainment and employment $(25,26)$. Although there are few best or promising practices for targeted public health policy and systems changes that address these disparities for LGB individuals, research suggests that systems-level policies that reduce stigma and systematic discrimination should reduce unhealthy behaviors $(27,28)$. A study by Hatzenbuehler et al found an increase in mood disorders, generalized anxiety disorders, alcohol use, and psychiatric comorbidity over time among LGB people living in states with gay marriage bans, which was not observed among LGB people living in states without bans (29). In contrast, gay men in legally recognized civil unions have significantly greater social and emotional support and better access to health insurance and quality health care (15). A study in Massachusetts reported significant decreases in medical and mental health care visits and costs among gay men in the 12-month period after the enactment of a law granting marriage equality (30). One possible conclusion is that any public health interventions targeted directly to the LGB community may be ineffective if delivered in a climate of systematic discrimination.

\footnotetext{
The opinions expressed by authors contributing to this journal do not necessarily reflect the opinions of the U.S. Department of Health and Human Services, the Public Health Service, the Centers for Disease Control and Prevention, or the authors' affiliated institutions.
} 
This study had several limitations. The BRFSS sampling methods used during the period of this study excluded people living in homes without a landline telephone, those with only cellular telephone service, those living in institutions, and those who do not speak English or Spanish. Because of the small sample size, we were unable to adjust for race and ethnicity in the analysis and were unable to analyze depression among LGB people. Another limitation of this study was that sexual orientation was self-reported. Some LGB individuals may have been unwilling to describe themselves as gay, lesbian, or bisexual on a telephone survey. Dilley et al provide additional details on the limitations of the BRFSS for analysis of the LGB population (4). Future studies could include race and ethnicity, legal domestic partnership and marriage, and a more granular gradient of rural and urban residency as potential adjustment factors, and could include mental health conditions as a dependent variable in analysis.

We found disparities in chronic conditions and health limitations, health risk factors, and protective health practices among LGB men and women. These disparities were most prominent among lesbian and bisexual women, and gay men had the most protective health practices. However, compared with heterosexual men, gay men were more likely to engage in risky behaviors that lead to chronic diseases later in life, and lower prevalence of obesity is likely a result of negative body image. We confirm some of the LGB health disparities identified in previous studies and find additional areas to target tailored public health interventions. Stigma and discrimination may increase LGB individuals' engagement in unhealthy behaviors, such as tobacco and alcohol use. Targeted public health interventions are likely most effective at improving health outcomes for LGB individuals if they are provided in systems that avoid stigmatizing and discriminating against LGB individuals where they live, work, learn, and socialize.

\section{Acknowledgments}

This study was supported by CDC cooperative agreement nos. U59/EH000506, U58/DP003980, and U50/DP000726. We thank Karen Girard, Bruce Gutelius, Katrina Hedberg, and Stacey Schubert for their contributions to this article. The authors have no competing interests to report.

\section{Author Information}

Corresponding Author: Rodney Y. Garland-Forshee, MS, Oregon Health Authority, Oregon Public Health Division, 800 NE Oregon St, Suite 730, Portland OR 97232. Telephone: 971-673-1348. Email: rodney.garland@state.or.us.
Author Affiliations: Steven C. Fiala, Duyen L. Ngo, Katarina Moseley, Oregon Health Authority, Portland, Oregon.

\section{References}

1. Boehmer U. Twenty years of public health research: inclusion of lesbian, gay, bisexual, and transgender populations. Am J Public Health 2002;92(7):1125-30.

2. Institute of Medicine. The health of lesbian, gay, bisexual, and transgender people: building a foundation for better understanding. Washington (DC): The National Academies Press; 2011.

3. Conron KJ, Mimiaga MJ, Landers SJ. A population-based study of sexual orientation identity and gender differences in adult health. Am J Public Health 2010;100(10):1953-60.

4. Dilley JA, Simmons KW, Boysun MJ, Pizacani BA, Stark MJ. Demonstrating the importance and feasibility of including sexual orientation in public health surveys: health disparities in the Pacific Northwest. Am J Public Health 2010;100(3):460-7.

5. Cochran SD, Mays VM. Physical health complaints among lesbians, gay men, and bisexual and homosexually experienced heterosexual individuals: results from the California Quality of Life survey. Am J Public Health 2007;97(11):2048-55.

6. Fredriksen-Goldsen KI, Kim H, Barkan SE, Balsam KF, Mincer SL. Disparities in health-related quality of life: a comparison of lesbians and bisexual women. Am J Public Health 2010;100(11):2255-61.

7. Diamant AL, Schuster MA, Lever J. Receipt of preventive health care services by lesbians. Am J Prev Med 2000; 19(3):141-8.

8. Gruskin EP, Gordon N. Gay/lesbian sexual orientation increases risk for cigarette smoking and heavy drinking among members of a large Northern California health plan. BMC Public Health 2006;6:241. http://www.biomedcentral.com/ 1471-2458/6/241. Accessed February 19, 2014.

9. US Department of Health and Human Services. Healthy people 2020. Lesbian, gay, bisexual, and transgender health. http:// www.healthypeople.gov/2020/topicsobjectives $2020 /$ overview.aspx?topicId=25. Accessed April 30, 2012.

10. WWAMI Rural Health Research Center. Version 2.0 codes for 2006 ZIP codes. http://depts.washington.edu/uwruca/ index.php. Accessed February 27, 2012.

11. Centers for Disease Control and Prevention. Prevalence of fruit and vegetable consumption and physical activity by race/ ethnicity — United States, 2005. MMWR Morb Mortal Wkly Rep 2007;56(13):301-4.

12. Eberhardt MS, Pamuk ER. The importance of place of residence: examining health in rural and nonrural areas. Am J Public Health 2004;94(10):1682-6.

The opinions expressed by authors contributing to this journal do not necessarily reflect the opinions of the U.S. Department of Health and Human Services, the Public Health Service, the Centers for Disease Control and Prevention, or the authors' affiliated institutions. 
13. Hartley D. Rural health disparities, population health, and rural culture. Am J Public Health 2004;94(10):1675-8.

14. Stimpson JP, Wilson FA, Peek MK. Marital status, the economic benefits of marriage, and days of inactivity due to poor health. Int J Popul Res 2012; 2012:568785. http:// www.hindawi.com/journals/ijpr/2012/568785/. Accessed February 19, 2014.

15. Solomon SE, Rothblum ED, Balsam KF. Pioneers in partnership: lesbian and gay male couples in civil unions compared with those not in civil unions and married heterosexual siblings. J Fam Psychol 2004;18(2):275-86.

16. Cherlin AJ. Health, marriage, and same-sex partnerships. J Health Soc Behav 2013;54(1):64-6.

17. Danaei G, Ding EL, Mozaffarian D, Taylor B, Rehm J, Murray $\mathrm{C}$, et al. The preventable causes of death in the United States: comparative risk assessment of dietary, lifestyle, and metabolic risk factors. PLoS Med 2009;6(4):e1000058.

18. Mokdad AH, Marks JS, Stroup DF, Gerberding JL. Actual causes of death in the United States, 2000. JAMA 2004; 291(10):1238-45.

19. McArdle KA, Hill MS. Understanding body dissatisfaction in gay and heterosexual men: the roles of self-esteem, media, and peer influence. Men Masc 2013;11(5):511-32.

20. Ludwig MR, Brownell KD. Lesbians, bisexual women, and body image: an investigation of gender roles and social group affiliation. Int J Eat Disord 1999;25(1):89-97.

21. Huxley CJ, Clarke V, Halliwell E. A qualitative exploration of whether lesbian and bisexual women are "protected" from sociocultural pressure to be thin. J Health Psychol 2014; 19(2):273-84.

22. Fredriksen-Goldsen KI, Kim HJ, Barkan SE, Muraco A, HoyEllis CP. Health disparities among lesbian, gay, and bisexual older adults: results from a population-based study. Am J Public Health 2013;103(10):1802-9.

23. Schiller JS, Lucas JW, Ward BW, Peregoy JA. Summary health statistics for US adults: National Health Interview Survey 2010. Vital Health Stat 2012;10(252):1-207.

24. Pampel FC, Krueger PM, Denney JT. Socioeconomic disparities in health behaviors. Annu Rev Sociol 2010; 36:349-70.

25. Hatzenbuehler ML. How does sexual minority stigma "get under the skin"? A psychological mediation framework. Psychol Bull 2009;135(5):707-30.

26. Meyer IH. Prejudice, social stress, and mental health in lesbian, gay, and bisexual populations: conceptual issues and research evidence. Psychol Bull 2003;129(5):674-97.
27. Rostosky S, Riggle E, Horne S, Denton F, Huellemeier J. Lesbian, gay, and bisexual individuals' psychological reactions to amendments denying access to civil marriage. Am J Orthopsychiatry 2010;80(3):302-10.

28. Shulman J, Weck V, Schwing S, Smith T, Coale E. The pushpull of policy pressure: a qualitative exploration of the experiences of same-sex marriage policies among nonmetropolitan GLB individuals. J GLBT Fam Stud 2009; 5:340-65.

29. Hatzenbuehler ML, McLaughlin KA, Keyes KM, Hasin DS. The impact of institutional discrimination on psychiatric disorders in lesbian, gay, and bisexual populations: a prospective study. Am J Public Health 2010;100(3):452-9.

30. Herek GM. Legal recognition of same-sex relationships in the United States: a social science perspective. Am Psychol 2006; 61(6):607-21.

\footnotetext{
The opinions expressed by authors contributing to this journal do not necessarily reflect the opinions of the U.S. Department of Health and Human Services, the Public Health Service, the Centers for Disease Control and Prevention, or the authors' affiliated institutions.
} 


\section{Tables}

Table 1. Characteristics of Study Population, by Sex and Sexual Orientation, Oregon Behavioral Risk Factor Surveillance System, 2005-2008

\begin{tabular}{|c|c|c|c|c|c|c|c|c|}
\hline \multirow[b]{3}{*}{ Outcome } & \multicolumn{4}{|c|}{ Men } & \multicolumn{4}{|c|}{ Women } \\
\hline & \multicolumn{3}{|c|}{ Weighted \% } & \multirow[b]{2}{*}{$P^{a}$} & \multicolumn{3}{|c|}{ Weighted \% } & \multirow[b]{2}{*}{$p a$} \\
\hline & Heterosexual & Gay & Bisexual & & Heterosexual & Lesbian & Bisexual & \\
\hline \multicolumn{9}{|l|}{ Age, y } \\
\hline $18-34$ & 31.8 & 29.3 & 45.1 & \multirow{3}{*}{.003} & 28.8 & 26.9 & 62.3 & \multirow{3}{*}{$<.001$} \\
\hline $35-54$ & 38.1 & 50.0 & 33.1 & & 36.9 & 54.4 & 30.3 & \\
\hline$\geq 55$ & 30.1 & 20.8 & 21.8 & & 34.3 & 18.7 & 7.3 & \\
\hline \multicolumn{9}{|l|}{ Relationship status } \\
\hline $\begin{array}{l}\text { Married or a member of an } \\
\text { unmarried couple }\end{array}$ & 69.4 & 42.3 & 45.0 & \multirow{3}{*}{$<.001$} & 66.3 & 51.6 & 52.4 & \multirow{3}{*}{$<.001$} \\
\hline Formerly married & 11.8 & 10.7 & 15.8 & & 21.3 & 21.3 & 19.0 & \\
\hline Never married & 18.8 & 47.0 & 39.3 & & 12.4 & 27.1 & 28.6 & \\
\hline \multicolumn{9}{|l|}{ Education } \\
\hline$\leq$ High school graduate or GED & 36.9 & 23.7 & 36.0 & \multirow{3}{*}{.02} & 36.3 & 19.1 & 27.9 & \multirow{3}{*}{$<.001$} \\
\hline 1-3 college years & 27.2 & 28.8 & 28.7 & & 31.7 & 27.3 & 33.7 & \\
\hline$\geq 4$ college years & 35.9 & 47.4 & 35.3 & & 32.0 & 53.6 & 38.4 & \\
\hline \multicolumn{9}{|l|}{ Residency ${ }^{b}$} \\
\hline Urban & 69.4 & 79.2 & 78.6 & \multirow{2}{*}{.03} & 69.3 & 77.3 & 78.4 & \multirow{2}{*}{.01} \\
\hline Rural & 30.6 & 20.8 & 21.4 & & 30.7 & 22.7 & 21.6 & \\
\hline \multicolumn{9}{|l|}{ Employment status } \\
\hline Employed & 66.6 & 74.9 & 72.3 & \multirow{3}{*}{.09} & 51.0 & 73.9 & 57.0 & \multirow{3}{*}{$<.001$} \\
\hline Unemployed or unable to work & 10.8 & 9.5 & 9.6 & & 9.5 & 13.1 & 15.0 & \\
\hline Not in workforce & 22.6 & 15.6 & 18.1 & & 39.5 & 13.0 & 28.0 & \\
\hline \multicolumn{9}{|l|}{ Annual household income, $\$$} \\
\hline$<20,000$ & 11.1 & 11.0 & 17.0 & \multirow{3}{*}{.32} & 14.2 & 13.0 & 20.4 & \multirow{3}{*}{$<.001$} \\
\hline $20,000-49,999$ & 42.9 & 46.1 & 47.1 & & 44.9 & 46.6 & 55.8 & \\
\hline$\geq 50,000$ & 46.0 & 42.9 & 35.9 & & 40.8 & 40.4 & 23.8 & \\
\hline \multicolumn{9}{|l|}{ Race/ethnicity } \\
\hline White, non-Latino & 85.9 & 88.8 & 83.4 & \multirow{2}{*}{.51} & 86.7 & 81.6 & 85.8 & \multirow{2}{*}{.14} \\
\hline All other races and Latino ethnicity & 14.1 & 11.2 & 16.6 & & 13.3 & 18.4 & 14.2 & \\
\hline
\end{tabular}

Abbreviation: GED, general educational development.

a Calculated using a Pearson $x^{2}$ test.

${ }^{b}$ Rural or urban residency was determined using zip codes classified by Rural-Urban Commuting Area codes (10).

The opinions expressed by authors contributing to this journal do not necessarily reflect the opinions of the U.S. Department of Health and Human Services, the Public Health Service, the Centers for Disease Control and Prevention, or the authors' affiliated institutions. 
Table 2. Prevalence of Chronic Conditions and Health Limitations and the Association with Sexual Orientation, by Sex, Oregon Behavioral Risk Factor Surveillance System, 2005-2008

\begin{tabular}{|c|c|c|c|c|c|c|}
\hline \multirow[b]{2}{*}{ Characteristic } & \multicolumn{3}{|c|}{ Men } & \multicolumn{3}{|c|}{ Women } \\
\hline & Weighted \% (95\% Cl) & $\mathrm{AOR}^{\mathrm{a}}(95 \% \mathrm{Cl})$ & $P^{\mathrm{b}}$ & Weighted \% (95\% Cl) & $\mathrm{AOR}^{\mathrm{a}}(95 \% \mathrm{Cl})$ & $P^{b}$ \\
\hline \multicolumn{7}{|c|}{ Mental or physical health not good (on $\geq 7$ days during the past 30 days) } \\
\hline Heterosexual (Ref) & $16.5(15.4-17.7)$ & - & - & $17.3(16.5-18.2)$ & - & \\
\hline Gay or lesbian & $15.4(9.9-23.1)$ & $0.8(0.5-1.4)$ & .47 & $15.9(10.9-22.6)$ & $1.0(0.6-1.6)$ & .96 \\
\hline Bisexual & $17.2(9.1-29.9)$ & $1.1(0.6-2.4)$ & .73 & $24.6(18.0-32.6)$ & $2.0(1.3-3.1)$ & $<.001$ \\
\hline
\end{tabular}

Had cardiovascular disease ${ }^{c}$

\begin{tabular}{|l|r|r|r|r|r|r|}
\hline Heterosexual (Ref) & $8.0(7.5-8.7)$ & - & - & $6.2(5.8-6.6)$ & - & - \\
\hline Gay or lesbian & $6.0(3.2-10.8)$ & $0.9(0.5-1.7)$ & .73 & $4.0(2.1-7.5)$ & $1.0(0.5-1.9)$ & .88 \\
\hline Bisexual & $11.4(5.8-21.1)$ & $1.8(0.8-3.7)$ & .12 & $1.8(0.6-6.0)$ & $0.7(0.2-2.9)$ & .61 \\
\hline
\end{tabular}

Had high blood pressure

Heterosexual (Ref)

$27.2(25.6-28.9)$

Gay or lesbian

$17.9(10.7-28.2)$

$16.1(8.0-29.8)^{\mathrm{d}}$

\begin{tabular}{l|l}
$0.6(0.4-1.1)$ & .09 \\
\hline
\end{tabular}

$25.6(24.3-26.8)$

Bisexual

\begin{tabular}{l|l}
$0.5(0.2-1.1)$ & .09 \\
\hline
\end{tabular}

$22.9(13.8-35.7)$

$12.4(7.5-19.9)$

$1.2(0.6-2.4)$

Had high cholesterol

Heterosexual (Ref)

\begin{tabular}{|r|}
\hline $40.2(38.2-42.2)$ \\
\hline $33.3(20.2-49.8)$ \\
\hline $37.7(18.5-61.6)$ \\
\hline
\end{tabular}

$-$

$-$

36.6 (35.1-38.1)

Gay or lesbian

\begin{tabular}{l|r|}
\hline $1.0(0.5-1.7)$ & .88 \\
\hline $0.8(0.3-2.0)$ & .62
\end{tabular}

$42.2(29.2-56.5)$

$22.5(13.5-35.2)$

$0.9(0.5-1.7)$

.85

Bisexual

\section{Had diabetes}

Heterosexual (Ref)

Gay or lesbian

Bisexual

Had asthma

Heterosexual (Ref)

Gay or lesbian

Bisexual

\begin{tabular}{r|}
$6.9(6.4-7.4)$ \\
\hline $7.8(4.4-13.5)$ \\
\hline $2.3(0.7-7.0)$
\end{tabular}

$0.8(0.3-2.0)$

$22.5(13.5-35.2)$

\begin{tabular}{r|r|}
- & - \\
\hline $1.6(0.8-3.3)$ & .19 \\
\hline $0.9(0.5-1.7)$ & .81 \\
\hline
\end{tabular}


(continued)

Table 2. Prevalence of Chronic Conditions and Health Limitations and the Association with Sexual Orientation, by Sex, Oregon Behavioral Risk Factor Surveillance System, 2005-2008

\begin{tabular}{|l|r|r|r|r|r|r|}
\hline \multirow{2}{*}{ Characteristic } & \multicolumn{5}{|c|}{ Men } & \multicolumn{3}{c|}{ Women } \\
\cline { 2 - 7 } & Weighted \% (95\% Cl) & AOR (95\% Cl) & \multicolumn{1}{c|}{$P^{\mathrm{b}}$} & Weighted \% (95\% Cl) & AOR $^{\mathrm{a}}(\mathbf{9 5 \%} \mathrm{Cl})$ & $P^{\mathrm{b}}$ \\
\hline Heterosexual (Ref) & $21.6(20.8-22.4)$ & - & - & $24.8(24.1-25.4)$ & - & - \\
\hline Gay or lesbian & $26.9(20.6-34.2)$ & $1.3(0.9-1.9)$ & .23 & $36.6(29.6-44.3)$ & $1.9(1.3-2.6)$ & $<.001$ \\
\hline Bisexual & $29.6(20.7-40.3)$ & $1.6(1.0-2.7)$ & .049 & $34.5(28.1-41.6)$ & $2.3(1.7-3.2)$ & $<.001$ \\
\hline Had a disability (need special equipment) & \multicolumn{5}{|c|}{} \\
\hline Heterosexual (Ref) & $6.8(6.4-7.3)$ & - & - & $7.8(7.4-8.1)$ & - & - \\
\hline Gay or lesbian & $6.0(3.6-9.8)$ & $0.8(0.4-1.3)$ & .36 & $10.0(4.7-20.0)$ & $1.5(0.6-3.8)$ & .42 \\
\hline Bisexual & $10.8(6.2-18.2)$ & $1.8(1.0-3.3)$ & .07 & $6.4(4.3-9.6)$ & $1.7(1.1-2.7)$ & .03 \\
\hline
\end{tabular}

Abbreviations: $\mathrm{Cl}$, confidence interval; $\mathrm{AOR}$, adjusted odds ratio; Ref, reference variable; - , not applicable.

a Odds ratio is adjusted for age, education, relationship status, and urban or rural residency.

${ }^{\mathrm{b}}$ Calculated using logic regression modeling.

${ }^{c}$ Cardiovascular disease included respondents who had ever had a heart attack, angina or coronary heart disease, or a stroke.

d This number's coefficient of variance was greater than $30 \%$ and therefore may be statistically unreliable and should be interpreted with caution. 
Table 3. Prevalence of Health Risk Factors and Protective Health Practices and the Association With Sexual Orientation, by Sex, Oregon Behavioral Risk Factor Surveillance System, 2005-2008

\begin{tabular}{|c|c|c|c|c|c|c|}
\hline \multirow[b]{2}{*}{ Characteristic } & \multicolumn{3}{|c|}{ Men } & \multicolumn{3}{|c|}{ Women } \\
\hline & Weighted \% (95\% Cl) & $\mathrm{AOR}^{\mathrm{a}}(95 \% \mathrm{Cl})$ & $P^{\mathrm{b}}$ & Weighted \% (95\% Cl) & $\mathrm{AOR}^{\mathrm{a}}(95 \% \mathrm{Cl})$ & $P^{\mathrm{b}}$ \\
\hline \multicolumn{7}{|c|}{ Health risk factors ${ }^{c}$} \\
\hline \multicolumn{7}{|c|}{ Current cigarette smoker } \\
\hline Heterosexual (Ref) & $18.6(17.7-19.4)$ & - & - & $15.3(14.7-15.9)$ & - & - \\
\hline Gay or lesbian & $22.9(16.9-30.1)$ & $1.2(0.8-1.8)$ & .29 & $22.5(15.7-31.1)$ & $1.6(1.1-2.3)$ & .02 \\
\hline Bisexual & $31.4(21.2-43.6)$ & $1.9(1.1-3.2)$ & .02 & $37.3(29.3-43.9)$ & $2.8(2.0-3.9)$ & $<.001$ \\
\hline \multicolumn{7}{|l|}{ Obese } \\
\hline Heterosexual (Ref) & $25.2(24.4-26.1)$ & - & - & $24.2(23.5-24.9)$ & - & - \\
\hline Gay or lesbian & $15.7(11.3-21.4)$ & $0.6(0.4-0.9)$ & .01 & $32.8(26.9-39.3)$ & $1.6(1.2-2.1)$ & .002 \\
\hline Bisexual & $22.0(14.4-32.1)$ & $0.9(0.5-1.5)$ & .68 & $33.7(24.8-42.4)$ & $1.7(1.2-2.4)$ & .001 \\
\hline \multicolumn{7}{|l|}{ Binge drinker } \\
\hline Heterosexual (Ref) & $18.7(17.6-19.9)$ & - & - & $8.9(8.2-9.6)$ & - & - \\
\hline Gay or lesbian & $31.9(22.0-43.8)$ & $1.8(1.1-3.1)$ & .02 & $16.4(10.4-25.0)$ & $1.7(1.0-3.0)$ & .054 \\
\hline Bisexual & $34.2(21.3-49.9)$ & $2.1(1.0-4.2)$ & .04 & $25.4(17.2-35.8)$ & $2.5(1.5-4.1)$ & .001 \\
\hline \multicolumn{7}{|l|}{ Heavy drinker } \\
\hline Heterosexual (Ref) & $5.5(4.9-6.2)$ & - & - & $5.6(5.1-6.2)$ & - & - \\
\hline Gay or lesbian & $10.2(5.3-18.7)$ & $1.8(0.9-3.7)$ & .13 & $8.5(4.7-14.9)$ & $1.4(0.7-2.7)$ & .31 \\
\hline Bisexual & $4.4(1.6-11.6)$ & $0.7(0.2-2.1)$ & .54 & $7.1(3.8-13.0)$ & $1.3(0.6-2.5)$ & .51 \\
\hline \multicolumn{7}{|c|}{ Protective health practices } \\
\hline \multicolumn{7}{|c|}{ Had health insurance ${ }^{d}$} \\
\hline Heterosexual (Ref) & $82.6(81.6-83.6)$ & - & - & $87.1(86.3-87.7)$ & - & - \\
\hline Gay or lesbian & $79.6(71.9-85.7)$ & $0.8(0.5-1.3)$ & .41 & $91.1(86.9-94.1)$ & $1.5(0.9-2.4)$ & .10 \\
\hline Bisexual & $80.5(67.0-89.4)$ & $1.3(0.6-2.6)$ & .52 & $71.4(62.6-78.9)$ & $0.5(0.3-0.7)$ & .001 \\
\hline \multicolumn{7}{|c|}{ Had health checkup in past 2 years } \\
\hline Heterosexual (Ref) & $70.6(69.6-71.6)$ & - & - & $82.2(81.5-82.9)$ & - & - \\
\hline Gay or lesbian & $69.9(61.6-77.0)$ & $1.0(0.7-1.5)$ & .93 & $78.0(69.4-84.8)$ & $0.8(0.6-1.3)$ & .40 \\
\hline Bisexual & $64.3(52.4-74.6)$ & $0.8(0.5-1.3)$ & .40 & $66.3(58.9-73.1)$ & $0.5(0.4-0.7)$ & $<.001$ \\
\hline
\end{tabular}

Abbreviation: $\mathrm{Cl}$, confidence interval; $\mathrm{AOR}$, adjusted odds ratio; Ref, reference variable; - , not applicable; HIV, human immunodeficiency virus; CDC, Centers for Disease Control and Prevention.

a Odds ratio is adjusted for age, education, relationship status, and urban or rural residency.

${ }^{b}$ Calculated using logic regression modeling.

${ }^{\mathrm{c}}$ Current cigarette smokers were defined as having smoked 100 or more cigarettes in their lifetime and currently smoking cigarettes on some or all days. Obesity was established for respondents who had a body mass index (weight in kilograms divided by the square of height in meters) of $30 \mathrm{~kg} / \mathrm{m}^{2} \mathrm{or} \mathrm{higher}$. CDC defines heavy drinking as consuming more than 1 drink per day on average in the last month for women and consuming more than 2 drinks per day on average in the last month for men. CDC defines binge drinking as consuming 4 or more drinks during 1 occasion in the last month for women and consuming 5 or more drinks during 1 occasion in the last month for men.

d Data were not available in 2008.

(continued on next page)

The opinions expressed by authors contributing to this journal do not necessarily reflect the opinions of the U.S. Department of Health and Human Services, the Public Health Service, the Centers for Disease Control and Prevention, or the authors' affiliated institutions. 
(continued)

Table 3. Prevalence of Health Risk Factors and Protective Health Practices and the Association With Sexual Orientation, by Sex, Oregon Behavioral Risk Factor Surveillance System, 2005-2008

\begin{tabular}{|c|c|c|c|c|c|c|}
\hline \multirow[b]{2}{*}{ Characteristic } & \multicolumn{3}{|c|}{ Men } & \multicolumn{3}{|c|}{ Women } \\
\hline & Weighted \% (95\% Cl) & $\operatorname{AOR}^{\mathrm{a}}(95 \% \mathrm{Cl})$ & $P^{\mathrm{b}}$ & Weighted \% (95\% Cl) & AOR $^{a}(95 \% \mathrm{Cl})$ & $P^{\mathrm{b}}$ \\
\hline \multicolumn{7}{|c|}{ Got influenza immunization } \\
\hline Heterosexual (Ref) & $28.9(27.8-30.0)$ & - & - & $36.2(35.3-37.2)$ & - & - \\
\hline Gay or lesbian & $42.9(33.4-53.0)$ & $2.5(1.5-4.0)$ & $<.001$ & $33.5(24.1-44.5)$ & $1.1(0.6-2.0)$ & .69 \\
\hline Bisexual & $26.6(15.6-41.6)$ & $1.1(0.5-2.4)$ & .82 & $22.8(15.0-33.1)$ & $0.9(0.5-1.6)$ & .70 \\
\hline \multicolumn{7}{|l|}{ Ever tested for HIV } \\
\hline Heterosexual (Ref) & $33.6(32.1-35.1)$ & - & - & $37.6(36.3-38.8)$ & - & - \\
\hline Gay or lesbian & $73.4(60.9-83.1)$ & $5.4(3.0-9.7)$ & $<.001$ & $45.9(36.9-55.2)$ & $1.3(0.9-2.0)$ & .14 \\
\hline Bisexual & $67.0(49.6-80.7)$ & $4.1(1.9-8.8)$ & $<.001$ & $66.3(56.2-75.1)$ & $2.6(1.7-4.2)$ & $<.001$ \\
\hline \multicolumn{7}{|c|}{ Checked cholesterol in past 5 years } \\
\hline Heterosexual (Ref) & $67.4(65.3-69.5)$ & - & - & $72.9(71.1-74.6)$ & - & - \\
\hline Gay or lesbian & $79.3(66.5-88.1)$ & $2.0(0.9-4.7)$ & .10 & $75.5(58.0-87.3)$ & $1.1(0.6-2.1)$ & .80 \\
\hline Bisexual & $65.0(43.3-81.9)$ & $0.9(0.5-1.8)$ & .77 & $62.7(48.5-74.9)$ & $1.5(0.6-3.5)$ & .37 \\
\hline \multicolumn{7}{|c|}{ Met CDC fruit and vegetable recommendations } \\
\hline Heterosexual (Ref) & $20.4(19.1-21.9)$ & - & - & $32.3(31.0-33.6)$ & - & - \\
\hline Gay or lesbian & $26.1(16.3-39.0)$ & $1.4(0.8-2.6)$ & .23 & $31.0(22.3-41.2)$ & $0.9(0.6-1.4)$ & .58 \\
\hline Bisexual & $28.0(14.7-46.7)$ & $1.6(0.7-3.7)$ & .27 & $35.5(24.2-48.7)$ & $1.1(0.6-2.1)$ & 68 \\
\hline
\end{tabular}

Met CDC physical activity recommendations

\begin{tabular}{|l|r|r|r|r|r|r|}
\hline Heterosexual (Ref) & $57.4(55.7-59.2)$ & - & - & $55.7(54.3-57.1)$ & - & - \\
\hline Gay or lesbian & $57.8(45.5-69.3)$ & $1.0(0.6-1.6)$ & .91 & $50.4(39.5-61.2)$ & $0.8(0.5-1.2)$ & .24 \\
\hline Bisexual & $59.8(39.6-77.1)$ & $1.0(0.5-2.3)$ & .96 & $53.7(41.4-65.6)$ & $0.8(0.5-1.3)$ & .35 \\
\hline
\end{tabular}

Had teeth cleaned in past 12 months

Heterosexual (Ref)

Gay or lesbian

Bisexual
$66.0(64.3-67.7)$ $68.9(54.1-80.6)$ $48.9(29.7-68.5)$

\begin{tabular}{r|r|r|r|}
\hline 6) & - & - & \\
\hline 5$)$ & $1.2(0.6-2.4)$ & .64 & \\
\hline $0.5(0.2-1.1)$ & .09 & \\
\hline
\end{tabular}

$68.9(67.6-70.2)$

$59.5(48.4-69.8)$

$43.3(30.9-56.6)$

\begin{tabular}{l|r|}
\hline $0.5(0.3-0.9)$ & .01 \\
\hline $0.4(0.2-0.6)$ & $<.001$
\end{tabular}

Abbreviation: $\mathrm{Cl}$, confidence interval; AOR, adjusted odds ratio; Ref, reference variable; - , not applicable; HIV, human immunodeficiency virus; CDC, Centers for Disease Control and Prevention.

a Odds ratio is adjusted for age, education, relationship status, and urban or rural residency.

${ }^{\mathrm{b}}$ Calculated using logic regression modeling.

${ }^{\mathrm{C}}$ Current cigarette smokers were defined as having smoked 100 or more cigarettes in their lifetime and currently smoking cigarettes on some or all days. Obesity was established for respondents who had a body mass index (weight in kilograms divided by the square of height in meters) of $30 \mathrm{~kg} / \mathrm{m}^{2} \mathrm{or} \mathrm{higher}$. CDC defines heavy drinking as consuming more than 1 drink per day on average in the last month for women and consuming more than 2 drinks per day on average in the last month for men. CDC defines binge drinking as consuming 4 or more drinks during 1 occasion in the last month for women and consuming 5 or more drinks during 1 occasion in the last month for men.

${ }^{d}$ Data were not available in 2008.

The opinions expressed by authors contributing to this journal do not necessarily reflect the opinions of the U.S. Department of Health and Human Services, the Public Health Service, the Centers for Disease Control and Prevention, or the authors' affiliated institutions. 